\title{
Fibrossarcoma de ducto biliar em gato
}

\author{
Biliary duct fibrosarcoma in cat \\ Marcelo Seixo de Brito e Silva ${ }^{1}$, Aline Moraes Faria ${ }^{2}$, Mariana Moreira Andraschko², \\ Marina Pacheco Miguel ${ }^{3}$, Tatyane Penha Sales ${ }^{4}$, Viviane Souza $\mathrm{Cruz}^{1}$, \\ Neusa Margarida Paulo ${ }^{5} \&$ Liliana Borges de Menezes ${ }^{6}$
}

\begin{abstract}
RESUMO
Fibrossarcoma felino é uma neoplasia maligna, localmente invasiva e de tecido conjuntivo fibroso que, em alguns gatos, está associada à vacinação, particularmente a vacinas com adjuvantes. Ocasionalmente, fibrossarcoma aparece naturalmente, não associado à vacina. $\mathrm{O}$ presente artigo relata o caso de um felino macho de 10 anos de idade, com um histórico de emagrecimento crônico há alguns meses e aumento do volume abdominal cranial. Através de exames ultrassonográfico e radiográfico, identificou-se uma massa na região hipogástrica e diante do quadro, encaminhou-se o animal à laparotomia exploratória. A neoplasia localizava-se na região do ducto biliar e uma segunda massa solitária foi identificada no lobo caudado do fígado. Houve a remoção cirúrgica dos tumores e a coleta de amostras para exame histopatológico. De acordo com os achados dos exames por imagem, avaliação macroscópica e histopatológica, o diagnóstico foi fibrossarcoma primário de ducto biliar.
\end{abstract}

Descritores: ducto biliar, fibrossarcoma felino, neoplasia maligna.

ABSTRACT

Feline Fibrosarcoma is a malignant neoplasia of conjunctive tissue that in some cats, is associated with the vaccination, particularly vaccines with adjuvant. Occasionally the tumor appears naturally with no association to the vaccine. The present article reports a case of a 10 years old, male, feline, that presented cronic slimming and a cranial abdominal volume increase. Through ultrasonographic and radiographic examinations, a mass in the hipogastric region was identified, and ahead oh the case, the animal was directed to the exploratory laparotomia. The neoplasia was situated in the biliary duct region and one second solitary mass was identified in the liver's caudal lobe. The tumors was surgically removed and samples was harvested for histopatologic examination. In accordance with the findings of the examinations for image, macrocospic and histopathologic evaluation the diagnosis was primary biliary duct fibrosarcoma.

Keywords: biliary duct, feline fibrosarcoma, malignant neoplasia. 


\section{INTRODUÇÃO}

Em geral, os fibrossarcomas são neoplasias malignas de fibroblastos, os quais produzem variada quantidade de fibras colágenas [3]. Existem três variantes deste tipo de tumor: a forma solitária, a forma multicêntrica e a forma associada à aplicação de vacinas e outros medicamentos injetáveis [5]. Esta neoplasia é a mais comum em derme e tecido subcutâneo de gatos e tem aumentado sua frequência devido à associação com vacinação [3], nesses casos o tumor se desenvolve no local da vacinação [1]. Os fibrossarcomas solitários geralmente são firmes, de crescimento lento, podendo ocorrer em qualquer parte do corpo, entretanto, no fígado e nos ductos biliares são de ocorrência rara [1,3]. Os animais senis são mais frequentemente acometidos apesar de existirem relatos em gatos com menos de seis meses [3].

Devido aos poucos relatos, não há definição de predisposição por sexo e idade, e não foram descritas características clínicas específicas [2]. Sua etiologia ainda não foi totalmente definida, porém, experimentalmente, essas neoplasias já foram induzidas pelo uso da dietilnitrosamina [6] e, em gatos jovens, pelo sarcomavirus felino (FeSV), forma mutante do vírus da leucemia felina [3].

Desta forma, o objetivo deste trabalho é relatar um caso de fibrossarcoma em ducto biliar em um gato.

\section{RELATO DE CASO}

Foi atendido no Hospital Veterinário das Faculdades Objetivo um felino de 10 anos, macho, não castrado, que convivia, em uma casa, com outros 6 gatos e apresentava histórico de emagrecimento crônico há

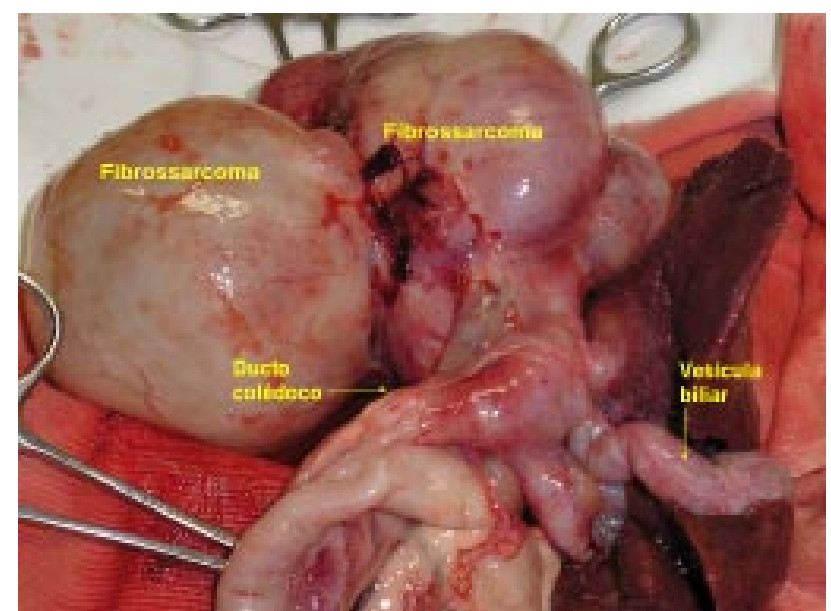

Figura 1. Tumor bilobulado, bem delimitado de superfície lisa e coloração branco-amarelada localizado na região do ducto biliar. alguns meses com aumento considerável de volume abdominal cranial. O animal se alimentava com dificuldade e em pequena quantidade, não houve perda de apetite, defecava muito pouco e o consumo de água era normal.

O mesmo foi submetido a exames ultrassonográficos que identificaram uma massa vesicular bilobulada na região hipogástrica de aproximadamente $9 \mathrm{~cm}$ de diâ-metro no seu eixo maior. As imagens radiográficas confirmaram esta posição e identificação, não identificando outras massas no tórax ou no abdômen. O hemograma indicava anemia normocítica normocrômica.

Diante do quadro, o animal foi encaminhado para ser examinado através de laparotomia exploratória, para avaliação e possível extirpação da massa vesicular. O tumor primário localizava-se na região do ducto biliar e uma segunda massa solitária foi identificada no lobo caudado do fígado. Houve a remoção cirúrgica dos tumores e a coleta de amostras para exame histopatológico. Durante o retorno anestésico, o animal veio a óbito.

\section{DISCUSSÃO}

$\mathrm{Na}$ análise radiográfica não foram identificados outras massas neoplásicas no tórax e no abdômen, desta forma, descartou-se a possível origem metastática da neoplasia. A maior dificuldade no diagnóstico de fibrossarcoma é definir a localização da neoplasia primária, sendo indispensável uma associação dos achados macroscópicos e microscópicos, visto que os dois possuem valor limitado quando não relacionados [2]. À laparotomia exploratória,observou-se um tumor bilobulado, bem delimitado, de consistência firme, superfície lisa e coloração branco-amarelada (Figura 1), sendo todas essas características também descritas por outros autores [6]. Microscopicamente, constatou-se a proliferação de células neoplásicas alongadas e ovaladas de tamanhos variados com citoplasma fracamente eosinofílico, apresentando núcleos de ovais a fusiformes e nucléolos proeminentes (Figura 2); a presença de fibras colágenas foi confirmada pela coloração especial de Mallory (Figura 3); atividade mitótica variando de moderada a acentuada; áreas de necrose e hemorragia multifocais; discreta proliferação de vasos sanguíneos e discreto infiltrado inflamatório linfocitário multifocal [4]. De acordo com os achados dos exames por imagem, avaliação macroscópica e histopatológica, o diagnóstico foi fibrossarcoma primário de ducto biliar. 


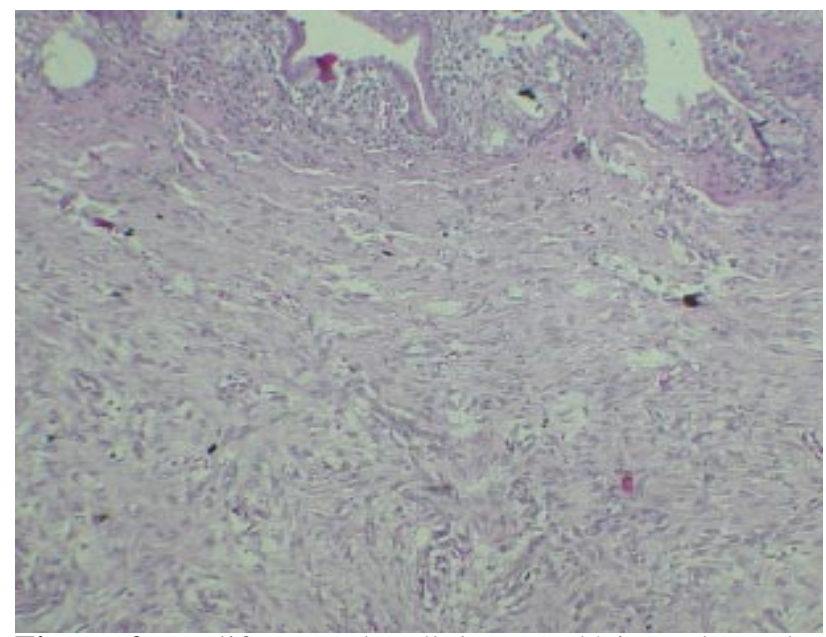

Figura 2. Proliferação de células neoplásicas alongadas ou ovaladas de tamanhos variados com produção de fibra colágena pouco densa. Presença de células do epitélio ductal (Coloração HE, 200x).

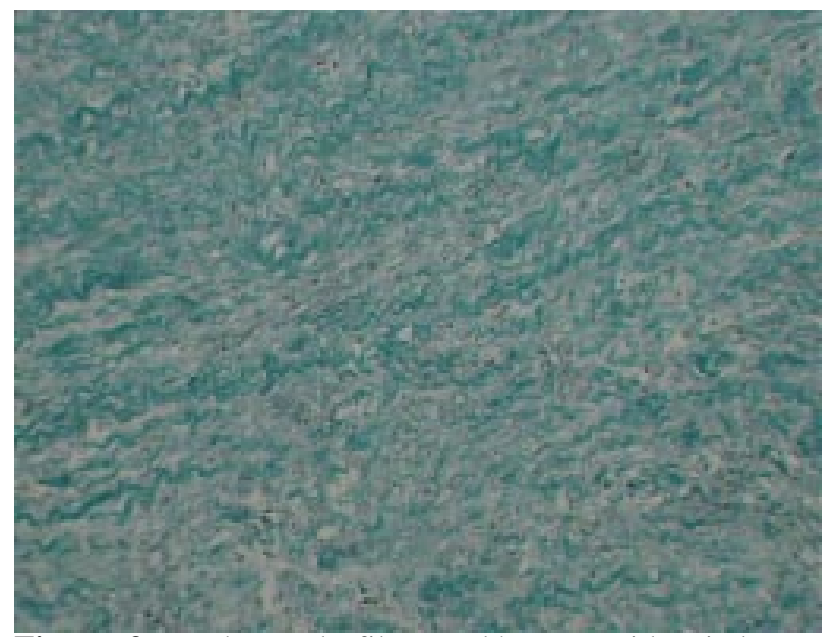

Figura 3. Produção de fibras colágenas evidenciada por coloração especial. Coloração de Mallory, 200x.

\section{REFERÊNCIAS}

1 Chalita M.C.C. \& Reche J.R. 2003. A. Fibrossarcoma. In: Souza H.J.M. (Ed.). Coletâneas em medicina e cirurgia felina. Rio de Janeiro: L.F. Livros de Veterinária Ltda., pp.215-224.

2 Cullen J.M. \& Popp J.A. 2002. Tumours of the liver and gall bladder. In: Meuten D.J. (Ed.). Tumors in domestic animals. 4th edn. Iowa State: University California Press, pp.483-508.

3 Goldschmidt M.H. \& Hendrick M.J. 2002. Tumours of the skin and soft tissues. In: Meuten D.J. (Ed.). Tumors in domestic animals. 4th edn. Iowa State: University California Press, pp.45-118

4 Martin M. 2003. Vaccine-associated fibrosarcoma in a cat. Canadian Veterinary Journal. 44: 660-663.

5 Ogilvie G.K. \& Moore A.S. 2001. Feline Oncology. A Comprehensive Guide to Compassionate Care. New Jersey: Veterinary Learning Systems, $503 \mathrm{p}$.

6 Popp J.A. 1990. Liver, gall badder, and pancreas. In: Moulton J.E. (Ed.). Tumor in domestic animals. 3rd edn. London: University California Press, pp.436-457. 